offered in early breast cancer then it becomes of paramount importance to consider the psychological impact of treatment to be offered.

The degree of psychosocial morbidity among the patients treated by local excision and radiotherapy was a disappointing finding, but one which cannot be ignored. These women clearly need just as much counselling support as patients who undergo mastectomy.

As more surgeons start to advocate breast conservation it is important that we have more basic research into the causal factors of the psychiatric morbidity experienced by women who receive this treatment.

We thank all the surgeons and radiotherapists who permitted access to their patients and the Cancer Research Campaign for financial support.

\section{References}

1 Fisher B, Bauer $M$, Margolese R. Five year results of a randomised clinical trial comparing total mastectomy and segmental mastectomy with or without radiation in the treatment of breas cancer. N Engl f Med 1985;312:665-73.

2 Morris T, Steven-Greer H, White P. Psychological and social adjustment to mastectomy (a 2-year follow-up study). Cancer 1977:40:2381-7.

3 Maguire GP, Lee EG, Bevington DJ, et al. Psychiatric problems in the year after mastectomy. $B r$ Med f 1978;i:963-5.

4 Ray C, Baum M. Psychological aspects of early breast cancer. New York: Springer-Verlag Inc, 1985

5 Sanger CK, Reznikoff $M$. A comparison of the psychological effects of breast-saving procedures with the modified mastectomy. Cancer 1981;48:2341-6.
6 Schain W, Edwards BK, Gorrell CR, et al. Psychosocial and physical outcomes of stage I breast cancer therapy: mastectomy $\mathrm{v}$ excisional biopsy and irradiation. Breast Cancer Res Treat

7 Steinberg MD, Juliano MA, Wise L. Psychological outcome of lumpectomy versus mastectomy in the treatment of breast cancer. Am $\mathcal{F}$ Psychiatry 1985;142:34-9.

8 Ashcroft JJ, Leinster SJ, Slade PD. Breast cancer-patient choice of treatment: preliminary $\widehat{\Omega}$ communication. I R Soc Med 1985;78:43-6.

9 Senescu RA. The development of emotional complications in the patient with cancer. $f$ Chronic Dis 1963;16:813-32.

10 Peck A, Boland J. Emotional reactions to radiation treatment. Cancer 1977;40:180-4.

11 Forester BM, Kornfeld RS, Fleiss J. Psychiatric aspects of radiotherapy. Am 7 Psychiatry 1978;135:960-3.

12 Holland JC, Rowland J, Lebovits A, Rusalem R. Reactions to cancer treatment: assessment of .emotional response to adjuvant radiotherapy as a guide to planned intervention. Psychiatr Clin $\overrightarrow{\overrightarrow{\vec{B}}}$ North Am 1979;2:347-58.

13 Peckham MJ (chairman). Protocol for a collaborative trial to evaluate the need for mastectomy in the management of early breast cancer. London: Cancer Research Campaign Clinical Trials Centre, manase

14 Wing JK, Cooper JE, Sartorious N. Measurement and classification of psychiatric symptoms. Cambridge: Cambridge University Press, 1974.

15 American Psychiatric Association. Diagnostic and statistical manual of mental disorder. 3rd ed. ®๐ Washington, DC: APA, 1980.

16 Zigmund AS, Snaith RP. The hospital anxiety and depression scale. Acta Psychiatr Scand ڤั 1983;67:370.

17 Pruyn JFA, Maguire P, De Haes JCJM. Two methods of measuring some aspects of quality of life. In: Quality of life methods of measurement and related areas. Proceedings of the second EORTC quality of life workshop. Copenhagen: European Organisation for the Research and Treatment of Cancer, 1981:52-5.

18 Ley P. Giving information to patients. In: Eiser JR, ed. Social psychology and behavioral science. Chichester: John Wiley and Sons Ltd, 1982:339-71.

19 Bransfield DD. Breast cancer and sexual functioning: a review of the literature and implications for future research. Int I Psychiatry Med 1982-3;12(3):197-211.

(Accepted 16 September 1986)

\title{
Optimising antiemesis in cancer chemotherapy: efficacy of continuous versus intermittent infusion of high dose metoclopramide in emesis induced by cisplatin
}

\author{
PAMELA S WARRINGTON, SIMON G ALLAN, MICHAEL A CORNBLEET, \\ JANET S MACPHERSON, JOHN F SMYTH, ROBERT C F LEONARD
}

\begin{abstract}
Thirty three untreated patients being given cisplatin received metoclopramide $(7 \mathrm{mg} / \mathrm{kg}$ ) for antiemesis by either continuous or intermittent infusion in a random order. Each patient received intravenous dexamethasone in addition. High pressure liquid chromatography was used to measure plasma concentrations of metoclopramide. The two regimens were evaluated for antiemetic efficacy and the incidence of side effects.

The intermittent metoclopramide regimen resulted in peak and trough plasma concentrations of metoclopramide with accumulation at eight hours, while the loading dose and continuous infusion resulted in mean plasma concentrations greater than $0.85 \mu \mathrm{g} / \mathrm{ml}(2.8 \mu \mathrm{mol} / \mathrm{l})$ throughout the eight hour period. The continuous infusion was associated with a significant improvement in nausea and vomiting and reduction in diarrhoea.
\end{abstract}

\footnotetext{
Imperial Cancer Research Fund Medical Oncology Unit, University Department of Clinical Oncology, Western General Hospital, Edinburgh EH4 2XU PAMELA S WARRINGTON, MSC, MPS, staff pharmacist SIMON G ALLAN, MB, MRCP, research fellow

MICHAEL A CORNBLEET, MD, MRCP, senior registrar

JANET S MACPHERSON, BSC, research officer

JOHN F SMYTH, MD, FRCP, professor of medical oncology

ROBERT C F LEONARD, MD, FRCPED, senior lecturer
}

Correspondence and requests for reprints to: Mrs Warrington.
Major control of emesis (two episodes or fewer) was achieved in 27 patients receiving continuous metoclopramide compared with 18 receiving intermittent metoclopramide.

\section{Introduction}

Current chemotherapy strategies still of necessity use highly emetogenic drugs. Clinical experience together with psychological studies confirm that the gastrointestinal sequelae of chemotherapy are of paramount importance. ${ }^{\prime}$ Cisplatin is one of the most emetogenic compounds known but is widely used in curative and $N$ palliative chemotherapy for cancer. Only recently have effective $\rightarrow$ antiemetics been developed, and much effort has been focused on the control of emesis induced by cisplatin: high dose meto- N clopramide given by intermittent infusion has proved useful, ${ }^{2-5}$ and N we showed that dexamethasone significantly enhances its antiemetic effect. ${ }^{6}$ In our previous study, however, only $65 \%$ of patients achieved major control (two or fewer episodes of vomiting); further improvement is required. Using an intermittent regimen, Meyer $\stackrel{\mathcal{\Phi}}{\rightarrow}$ et al found that effective antiemesis required a minimum plasma metoclopramide concentration of $0.85 \mu \mathrm{g} / \mathrm{ml}(2 \cdot 8 \mu \mathrm{mol} / \mathrm{l})$.

High dose intermittent infusion as reported by Gralla et al results not only in wide variations in plasma concentrations of the drug but also in accumulation. ${ }^{38}$ As a relation between plasma concentrations and antiemetic effect has been described failure of control may be the result of subtherapeutic concentration of metoclopramide at a critical time in the onset of vomiting, which is usually within two hours after the administration of cisplatin. 
We compared the antiemetic efficacy and side effects of a conventional intermittent infusion of metoclopramide with those of a loading dose and continuous infusion of metoclopramide designed to provide a constant drug concentration; in addition, we measured the plasma concentrations of metoclopramide achieved with both regimens.

\section{Patients and methods}

Thirty three previously untreated patients due to receive cisplatin were enrolled in the study. They comprised one man and 32 women (mean age $54 \cdot 2$ (range 30-68) years with tumours of the ovary ( 28 cases), cervix (two), bladder (one), prostate (one), and lung (one). Patients received cisplatin either alone (16 cases) or in combination with some of the following: fluorouracil, doxorubicin, methotrexate, mitozantrone, vindesine, prednimustine, and hexamethylmelamine. The dose of cisplatin was either 100 or $30 \mathrm{mg} / \mathrm{m}^{2}$ (25 and eight patients, respectively). Antiemetic, sedativehypnotic, and tranquillising drugs were stopped 24 hours before treatment. Patients with impaired renal function were excluded from the study, and therefore delayed elimination of metoclopramide would not be expected. ${ }^{9}$

Each patient received either a loading dose and a continuous infusion or an intermittent infusion of metoclopramide in a randomised sequence. The same total dose of metoclopramide, $7 \mathrm{mg} / \mathrm{kg}$, was given in both regimens. With both treatments dexamethasone $(20 \mathrm{mg}$ ) was given as a 15 minute infusion (in $0.9 \%$ sodium chloride $50 \mathrm{ml}$ ), beginning 30 minutes before cisplatin. The continuous metoclopramide regimen consisted of metoclopramide given as a loading dose of $3 \mathrm{mg} / \mathrm{kg}$ in $50 \mathrm{ml} 0.9 \%$ sodium chloride over 15 minutes before cisplatin, followed immediately by a continuous infusion of $4 \mathrm{mg} / \mathrm{kg}$ in $500 \mathrm{ml} 0.9 \%$ sodium chloride over eight hours. The doses of metoclopramide were calculated from standard pharmacokinetic equations to achieve plasma concentrations of approximately $0.85 \mu \mathrm{g} / \mathrm{ml}$ $(2 \cdot 8 \mu \mathrm{mol} / \mathrm{l}) .{ }^{10}$ With the intermittent infusion of metoclopramide the total dose, $7 \mathrm{mg} / \mathrm{kg}$, was made up to $500 \mathrm{ml}$ with $0.9 \%$ sodium chloride and administered in $100 \mathrm{ml}$ aliquots 15 minutes before cisplatin and thereafter on four occasions two hours apart.

Blood samples for estimation of plasma metoclopramide concentrations were taken at $0,0 \cdot 5,1,2,5$, and 8 hours in patients receiving the continuous regimen and at time 0 and immediately before and after the doses at 2, 4, 6 , and 8 hours in patients receiving the intermittent regimen to monitor peak and trough concentrations. Samples were collected in lithium-heparin tubes, and the plasma was stored at $-20^{\circ} \mathrm{C}$ until analysed.

Patient assessment-Standard questionnaires were completed in consultation with the patients 24 hours after the cisplatin was administered. Assessments were performed predominantly by one of us (PSW), with the patients recording their experience of nausea on a visual analogue scale: they were asked to indicate on a $10 \mathrm{~cm}$ line the severity of their nausea, $0 \mathrm{~cm}$ representing no nausea and $10 \mathrm{~cm}$ representing the most extreme nausea. The number of episodes of vomiting, retching, and diarrhoea was recorded by the patient and in interview with the nursing staff and the incidence of drowsiness, extrapyramidal effects, and akathisia documented. During their second admission for chemotherapy patients were asked the duration of nausea and vomiting after the administration of cisplatin.

Assay of metoclopramide-Metoclopramide concentration was measured by high performance liquid chromatography with a modification of the method of Taylor et al. ${ }^{11}$ Disopyramide was used as an internal standard, and metoclopramide was extracted from alkalinised plasma with dichloromethane. Calibration curves were linear with a coefficient correlation of $>0.998$. The detection limit was roughly $1 \mathrm{ng}$ metoclopramide $(100 \mathrm{ng} / \mathrm{ml}$ plasma), and the extraction recovery from plasma was $92-98 \%$.

\section{Results}

All 33 patients received both the intermittent and the continuous infusions. Metoclopramide concentrations were measured in plasma samples from 13 patients receiving the continuous infusion and 14 patients receiving the intermittent infusion.

Nausea as indicated on the visual analogue scale was significantly reduced $(p<0.0001$, Wilcoxon signed rank test) when the patients received the continuous metoclopramide infusion compared with the intermittent infusion (fig 1). There was no significant reduction in retching $(p<0 \cdot 1)$, although there was a trend towards better control with the continuous regimen. Vomiting was significantly better controlled $(p<0.05)$ by the continuous infusion, 27 patients having two episodes of vomiting or fewer compared with 18 receiving the intermittent infusion. Fifteen patients had three or more episodes of vomiting while receiving the intermittent infusion compared with only six patients receiving the continuous infusion (table I).
Table I shows the incidence of adverse reactions. Diarrhoea may have been a side effect of the cisplatin or the metoclopramide, or both. Only one patient experienced diarrhoea (one or more abnormally loose stools) while receiving the continuous metoclopramide regimen, compared with eight patients receiving the intermittent infusion $(p<0.05)$. There was no significant difference in the incidence of other side effects between the two

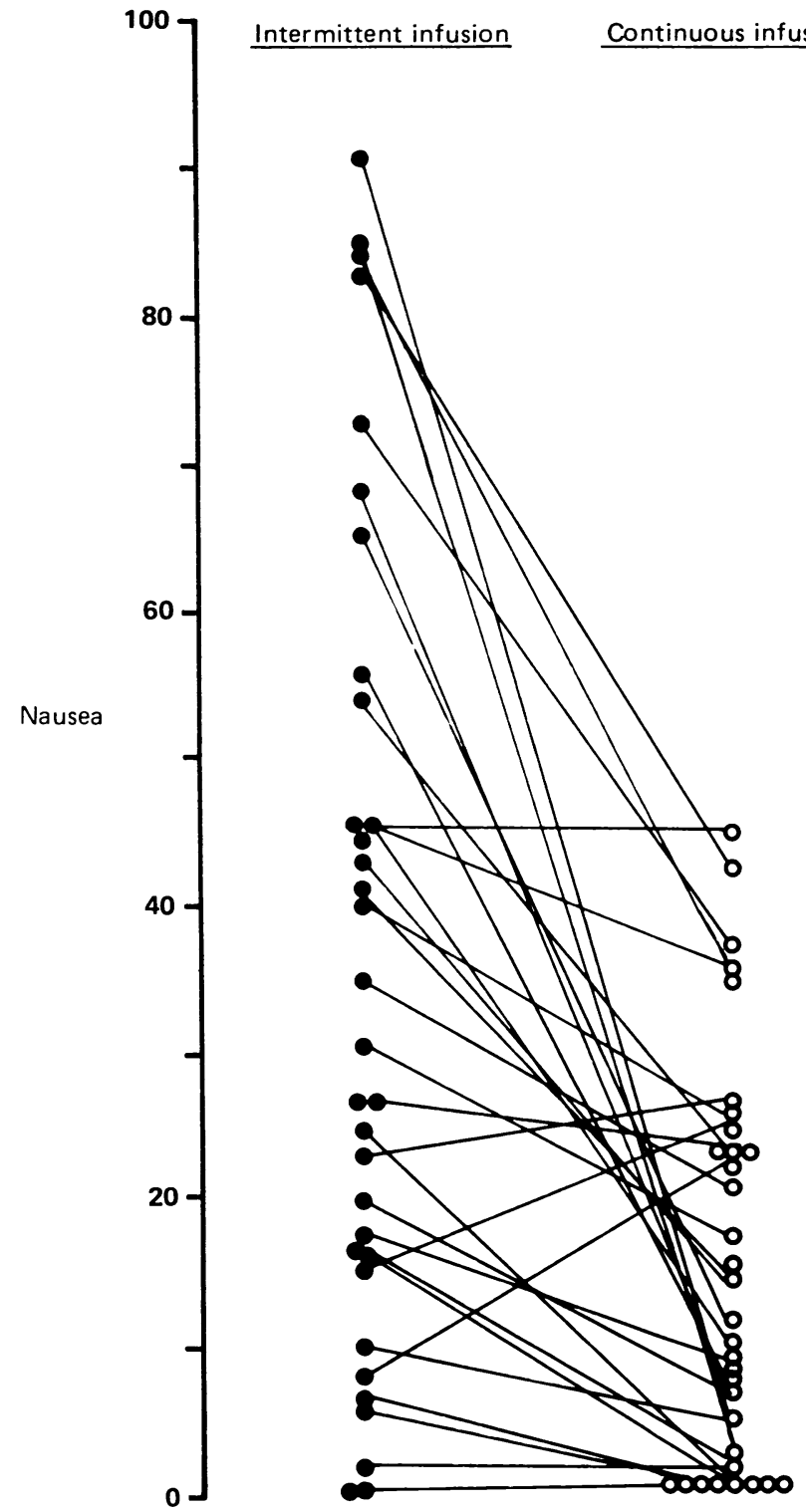

FIG 1-Changes in nausea experienced by individual patients as recorded on visual analogue scale. $0=$ No nausea; $100=$ severe nausea

TABLE I-Prevalence of side effects of treatment $(n=33)$

\begin{tabular}{|c|c|c|c|}
\hline & $\begin{array}{l}\text { Intermittent } \\
\text { infusion }\end{array}$ & $\begin{array}{l}\text { Continuous } \\
\text { infusion }\end{array}$ & Significance ${ }^{\star}$ \\
\hline \multicolumn{4}{|l|}{ Retching: } \\
\hline $0-2$ episodes & 21 & 28 & $\mathrm{p}<0.1$ \\
\hline$\geqslant 3$ episodes & 12 & 5 & \\
\hline \multicolumn{4}{|l|}{ Vomiting: } \\
\hline $0-2$ episodes & 18 & 27 & $\mathrm{p}<0.05$ \\
\hline$\geqslant 3$ episodes & 15 & 6 & \\
\hline Diarrhoea & 8 & 1 & $p=0.02$ \\
\hline Extrapyramidal reactions & 1 & & \\
\hline Tremulousness & 6 & 7 & $\mathrm{p}<0.9$ \\
\hline Drowsiness & 23 & 27 & $p<0.5$ \\
\hline Patient preferencet & 5 & 18 & $p<0.05$ \\
\hline
\end{tabular}

*All variables assessed with $\chi^{2}$ tést except diarrhoea, for which Fisher's exact test was used. †Ten patients expressed no preference. 
different methods of administration. Significantly more patients preferred the continuous to the intermittent infusion $(p<0.05) ; 10$ patients expressed no preference. With both regimens drowsiness was the most common side effect.

After the first course of chemotherapy 21 of the 33 patients ( 10 having received intermittent metoclopramide and 11 having received continuous metoclopramide) were assessed for delayed or prolonged nausea and vomiting. Nausea occurred in 17 patients $(81 \%)$, eight of whom had received continuous metoclopramide and nine intermittent metoclopramide. The nausea lasted for from one to 14 days (median three days) with both regimens. Vomiting lasted for from one to seven days (median two days) and was reported in 10 of the 21 patients (46\%) (four receiving the continuous infusion and six the intermittent infusion). There was no significant difference (table II) in the results obtained after the two methods of administration.

TABLE II-Prevalence of delayed or prolonged nausea and vomiting $(n=21)$

\begin{tabular}{lccc}
\hline & Nausea & Vomiting & $\begin{array}{c}\text { Significance } \\
\left(\chi^{2} \text { test }\right)\end{array}$ \\
\hline $\begin{array}{l}\text { Continuous infusion } \\
\text { Intermittent infusion }\end{array}$ & 8 & 4 & $\begin{array}{c}\mathrm{p}<0.75 \\
\mathrm{p}<0.90\end{array}$ \\
\hline
\end{tabular}

Figure 2 shows that the loading dose and continuous infusion of metoclopramide resulted in a mean plasma concentration of metoclopramide above $0.85 \mu \mathrm{g} / \mathrm{ml}(2.84 \mu \mathrm{mol} / \mathrm{l})$ throughout the eight hour period. The intermittent infusion of metoclopramide produced mean plasma concentrations below this value during the first four hours with accumulation of metoclopramide at eight hours.

\section{Discussion}

This study shows that the application of simple pharmacokinetic principles in the administration of high dose metoclopramide can optimise the drug's antiemetic effect in patients receiving cisplatin. Thus the incidence of nausea was reduced during the continuous metoclopramide arm compared with the intermittent infusion arm. Major control of vomiting (two episodes or fewer) was achieved in $82 \%$ of the patients during the continuous infusion arm and only $\stackrel{\varrho}{c}$ $55 \%$ during the intermittent infusion arm. As emesis in patients receiving cisplatin begins two to four hours after the start of the infusion ${ }^{11}$ the therapeutic goal should be to achieve adequate plasma concentrations of metoclopramide at an early stage. In this study $\mathbb{\Phi}$ none of the patients receiving the intermittent infusion had achieved $m$ plasma concentrations of metoclopramide $\geqslant 0.85 \mu \mathrm{g} / \mathrm{ml}$ before their $?$ dose at four hours and only one patient achieved this concentration before the dose at six hours.

These results support the findings of Meyer et al that plasma concentrations of metoclopramide $>0.85 \mu \mathrm{g} / \mathrm{ml}$ are necessary to achieve optimum antiemetic effect. ${ }^{7}$ Furthermore, our study clearly showed the superiority of the loading and maintenance dose in achieving early, effective, and sustained plasma concentrations. है McDermed et al, however, could not relate antiemetic effect to $\vec{\circ}$ metoclopramide concentrations in a study population receiving intermittent infusions of the drug. ${ }^{12}$ A previous study of ours failed to show a significantly enhanced antiemetic effect with increasing dose of intermittently infused metoclopramide at $3 \mathrm{mg} / \mathrm{kg}, 5 \mathrm{mg} / \mathrm{kg}$, or $10 \mathrm{mg} / \mathrm{kg}$, although there was a trend in favour of the higher doses. ${ }^{4}$ Possibly in these two studies wide variability in the plasma $\mathscr{\omega}$ concentrations of metoclopramide between patients, who were $\dot{\sigma}$ receiving metoclopramide by intermittent infusion, and the failure $\mathrm{N}$ to achieve adequate plasma concentrations in the first four hours of administration led to erratic antiemetic efficacy. In the present study the patients acted as their own control and received the same dose of cisplatin during each admission.

Plasma concentrations of metoclopramide achieved varied con- $N$ siderably between patients. The loading dose and continuous $z$ infusion produced plasma metoclopramide concentrations ranging from 0.62 to $2 \cdot 36 \mu \mathrm{g} / \mathrm{ml}(2 \cdot 1$ to $7 \cdot 9 \mu \mathrm{mol} / \mathrm{l})$. A loading dose of $3 \mathrm{mg} /$ $\mathrm{kg}$ produced plasma concentrations ranging from 0.77 to $2.36 \mu \mathrm{g} /$ $\mathrm{ml}(2.6$ to $7.9 \mu \mathrm{mol} / \mathrm{l})$, with only one patient having a concentration below $0.85 \mu \mathrm{g} / \mathrm{ml}(2.8 \mu \mathrm{mol} / \mathrm{l})$. In two patients in whom plasma metoclopramide concentrations fell below $0.85 \mu \mathrm{g} / \mathrm{ml}$ during the continuous maintenance infusion and the antiemetic effect was
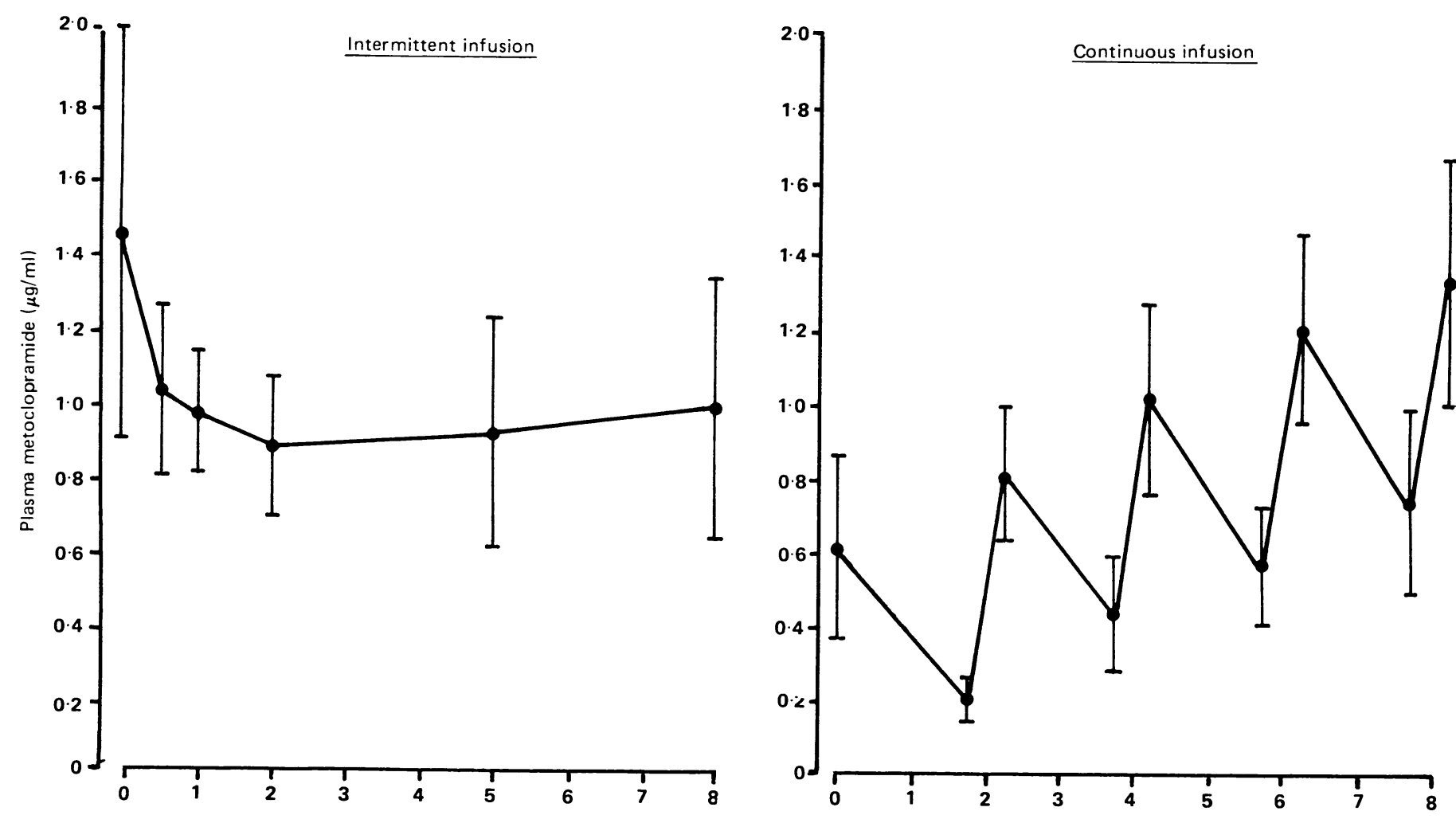

Time (hours)

FIG 2-Mean (SEM) plasma concentrations of metoclopramide after loading dose and continuous infusion and after intermittent infusion. 
poor, nausea and vomiting were reduced by increasing the dose of the maintenance infusion during subsequent treatment to 5 and $6 \mathrm{mg} / \mathrm{kg}$, respectively. This shows that the antiemetic effect of the drug can be optimised individually.

Neither regimen produced excessive side effects. Interestingly, diarrhoea was considerably reduced in the group receiving the continuous infusion, and it may be that wide fluctuations in plasma metoclopramide concentrations result in excessive intestinal hurry with resultant diarrhoea. Extrapyramidal reactions to metoclopramide are rare in this age group.

In view of an increasing tendency towards combination antiemetic treatment for emesis induced by cytotoxic drugs and the attendant concern over potential drug interactions the optimal use of individual antiemetics is considerably important. Thus we are encouraged by the considerable improvement in antiemetic effect achieved by high dose metoclopramide given as a loading dose and maintenance infusion after the application of simple pharmacokinetic principles. Future studies need to address the problems of the route and technique of administration of antiemetics and the dosage as well as identifying new compounds and combinations. Kris et al documented the time course of nausea and vomiting after administration of cisplatin. ${ }^{2}$ They showed that nausea persisted for five days in $40 \%$ of patients and vomiting in $20 \%$, with a peak incidence at three days after administration. In our study there was no difference in the duration of nausea and vomiting between the two arms, but the peak incidence of delayed nausea at three days agrees with the study of Kris et al. ${ }^{2}$ This suggests that control of acute emesis after cisplatin does not necessarily reduce subsequent delayed emesis, and thus further improvements are required.
We thank the pharmacy department and the nursing staff in the department of clinical oncology for their help in this study. We also thank Miss M E Kerr for statistical help.

\section{References}

1 Coates A, Abraham S, Kaye SB, et al. On the receiving end-patient perception of the side-effects of ancer chemotherapy. Eur 7 Cancer Clin Oncol 1983;19:203-8.

2 Kr KMG, Grall RA, Clark RA, al. Incidence, course and severity of delayed nausea and ( vomiting following the administration of high dose cis-platinum. I Clin Oncol 1985;3:1379-84. Gralla RJ, Litri LM, Pisko SE, et al. Anti-emetic efficacy of high dose metoclopramide randomised trial with placebo and prochlorperazine in patients with chemotherapy-induced nausea and vomiting. $N$ Engl $\mathcal{M}$ Med 1981;305:905-9.

4 Strum SB, McDermed JE, Opfell RW, Riech LP. Intravenous metoclopramide. An effective antiemetic in cancer chemotherapy. $\mathcal{F A M A ~ 1 9 8 2 ; 2 4 7 : 2 6 8 3 - 6 .}$

5 Allan SG, Cornbleet MA, Lockhart SP, Warrington PS, Leonard RCF, Smyth JF. Emesis due to cancer chemotherapy: results of a prospective, randomised, double-blind trial of varying doses of metoclopramide in the management of cis-platinum-induced vomiting. Eur $\mathrm{f}$ Cancer $\mathrm{Clin}$ Oncol 1984;20:1481-4.

6 Allan SG, Cornbleet MA, Warrington PS, Leonard RCF, Smyth JF. Dexamethasone and high dose metoclopramide effective in controlling cis-platinum-induced vomiting. $\mathrm{Br}$ Med $f$ 1984;289:878-9.

7 Meyer RB, Lewin M, Drayer DE, et al. Optimizing metoclopramide control of cis-platinuminduced emesis. Ann Intern Med 1984;100:363-5.

Taylor WB, Bateman DN. High dose metoclopramide-preliminary pharmacokinetic studies. $B r$ f Clin Pharmacol 1983;16:341-2.

9 Bateman DN, Gokal R, Dodds TRP, et al. The pharmacokinetics of single doses of metoclopramide in renal failure. Eur $\mathcal{F}$ Clin Pharmacol 1981;19:437-41.

10 Winter ME, Katcher BS, Koda-Kimble MA, eds. Basic clinical pharmacokinetics. San Francisco, Applied Therapeutics Inc, 1980:5-67.

1 Taylor WB, Proctor SJ, Bateman DN. Pharmacokinetics and efficacy of high-dose metoclopramide given by continuous infusion for the control of cytotoxic drug-induced vomiting. $\mathrm{Br} \mathcal{J}$ Clin Pharmacol 1984;18:679-84

12 McDermed JE, Cohen JL, Joseph C, Strum SB. Clinical pharmacokinetics of high dose metoclopramide in cancer patients receiving cisplatin therapy. $\mathcal{F}$ Clin Oncol 1985;3:1400-8.

Accepted 20 August 1986

\title{
Dose dependent response of symptoms, pituitary, and bone to transdermal oestrogen in postmenopausal women
}

\author{
P L SELBY, M PEACOCK
}

\begin{abstract}
The effect of the plasma oestradiol concentration on climacteric symptoms, gonadotrophin release, and bone resorption was studied in three groups of postmenopausal women given $\mathbf{0 . 0 2 5}$ $\mathrm{mg}, \mathbf{0 . 0 5} \mathrm{mg}$, or $\mathbf{0 . 1} \mathrm{mg}$ transdermal oestradiol daily. There was a dose related reduction in symptoms, plasma follicle stimulating hormone concentration, and urinary calcium and hydroxyproline excretion. The relation of the response to plasma oestradiol values was similar for each variable with an initial large reduction and little change in response to increases in the plasma oestradiol concentration above $150 \mathrm{pmol} / \mathrm{l}(41 \mathrm{pg} / \mathrm{ml})$.
\end{abstract}

Hormone replacement therapy producing an effect equivalent to higher oestradiol concentrations is likely to increase the risk of side effects without conferring any additional benefit.

MRC Mineral Metabolism Unit, The General Infirmary, Leeds LS1 3EX P L SELBY, MA, MRCP, honorary senior registrar M PEACOCK, MB, FRCP, acting director, honorary consultant physician

Correspondence to: Dr Peacock.

\section{Introduction}

Oestrogen replacement in postmenopausal women reduces both symptoms of the climacteric and excess bone resorption in a dose dependent manner. ${ }^{2}$ During the menstrual cycle, however, though the changes that occur in the plasma oestrogen concentration are of the same order of magnitude as those in women receiving postmenopausal hormone replacement therapy, they are not accompanied by any change in either oestrogen dependent symptoms or bone turnover. ${ }^{3}$ A possible explanation for this difference is that the response to oestrogen is near maximal at the plasma concentration present during menstruation and that only small changes in response occur with oestrogen concentrations within and above the premenopausal range.

If the response in bone to oestrogen has this relation it has implications for postmenopausal hormone replacement treatment, since the adverse effects of oestrogen treatment are dose related. ${ }^{14}$ Moreover, high doses of oestrogen have unwanted effects on bone as a result of inhibition of bone formation, which would be avoided by using the minimal dose of oestrogen to suppress resorption.

The establishment of such a dose has thus far been difficult because oestrogens are usually given by mouth. This causes hepatic "first pass" metabolism of the oestrogen, which appears in plasma as various metabolites with variable biological activity ${ }^{5}$ and increased concentrations of sex hormone binding globulin, which reduces the free hormone. ${ }^{6}$ Taken together these two phenomena make it impossible to assign any meaningful biological value 